\title{
Teacher Education Programs as Complex Organizations
}

\author{
LEONARD J. WAKS \\ Temple University (USA)
}

In "Reimagining Teacher Education" (RTE) Deborah Seltzer-Kelly and her co-authors bring a "complexity perspective" to teacher education, embracing a "complexity-based model" to "re-imagine the preparation of teachers" and to forestall deficit models of academic problems and oppositional attitudes of students. They also adopt a complexity-based method of inquiry, as Seltzer-Kelly, the lead author, preserves the "richness and variety of the multiple voices" of her co-authors while seeking to "draw them together" to "highlight some connections". This method (quoting A. P. Bochner) "gives up the illusions of transcendental observation in favor of the possibilities of dialogue and collaboration."

In what follows I comment briefly upon this unconventional method, consider the "rhetoric of equity and meritocracy" its authors locate as a primary source of deficit models, and provide an additional perspective on complexity-based teacher education.

\section{The Method of Inquiry}

The RTE authors provide a number of insightful observations. First, teaching is not a linear causal process but a complex interaction where attitudes and expectations of students and teachers are mutually determining. Second, teachers do not stand outside of, but rather shape, classroom situations, and like psychoanalysts using their awareness of the counter-transference, they can learn to use awareness of their complicity in the situation as a tool to clarify it. Third, postmodern philosophy is especially useful in deconstructing abstract categories and opening space for diverse voices. 
As useful as these insights are, it is not clear that Seltzer-Kelly is altogether successful in "drawing them together to highlight connections." Indeed, she appears ambivalent about this aim. Cautioning that "complexity discourse is not a metadiscourse that seeks to offer totalizing explanation" (Davis and Sumara), and that it seeks to avoid "leveling the world with a singular objectifying narrative voice" (Macbeth), Seltzer-Kelly asks us to rest content with the diversity of voices bringing a 'complexity perspective' to teacher education. She urges us to avoid the urge to reach a "fixed point" validated by a multiplicity of inquiries, and instead embrace and respond to a "crystallization' formed from "an infinite variety of shapes, substances, transmutations, multi-dimensionalities and angles of approach." "Understanding," she concludes, "is not the point."

I admit to finding this unsatisfactory. There can simply not be a diversity of voices without diverse voices; if every speaker refrained from making assertions, including those positioned to proffer useful syntheses, there would be nothing to "crystallize". There is a world of difference between putting forth tentative syntheses and "leveling the world" or issuing "transcendental observations" from nowhere. While one can learn something from a panel discussion, for example, it hardly follows that a tentative synthesis wipes out the differences among panelists or nullifies alternative perspectives.

I would have wished to learn more than Seltzer-Kelly says in her brief remarks on Bateson about how she and her co-authors conceive the "complexity perspective" and how it might reveal underlying similarities in their distinct contributions. In this regard it may be useful to recall how the complexity perspective itself took shape, as "noting profound similarities across a diversity of phenomena," such as the behavior of electrons, flocks of birds, and market prices (Waldrop, 1992). Early complexity theorists sought a perspective unifying this diversity of phenomena in terms of self-organized emergence. They did not rest content with merely pointing to diverse phenomena and inviting us to draw our own lessons. Bateson's preference for melding loose and strict thinking is helpful here: we make multiple speculations in diverse voices, then seek to draw from them a unifying model, not as a Platonic Form but as a useful heuristic for further inquiry.

\section{The Rhetorical Posture of Schooling, Teaching and Teacher Education}

For the RTE authors the primary source of the "blame game,' "the elephant" in the living room, is the chasm between classes obscured by the pervasive rhetoric of egalitarianism and meritocracy.

Let's grant that talk of schooling in terms of equity and meritocracy is a pack of outright lies: school districts in the same state can have, by law, almost unimaginable disparities in funding; ${ }^{1}$ schools and colleges, by their unequal granting of diplomas,

\footnotetext{
${ }^{1}$ See San Antonio Independent School District v. Rodriguez, 411 U.S. 1 (1973), in which the Supreme Court held that a school-financing system based on local property taxes did not violate the equal protection clause of the fourteenth amendment, because school financing systems, no mater how inequitable, were not subject to strict scrutiny.
} 
reproduce social inequality and create new forms of inequality between diploma holding 'middle class professionals' and their 'uneducated' counterparts. Suppose further that prospective teachers could grasp just how damaging social inequality and discrimination are to young 'underdog' children, destroying their self-esteem and undermining the positive philosophies of the future needed to motivate their present engagement in school. The teachers would stop blaming the children, just as they would stop blaming people for bumping into them upon seeing that those people were blind.

I wonder whether Seltzer-Kelly and her co-authors dig deeply enough into this rhetorical morass. When the rhetoric of equity and merit is pushed aside, it is possible to see schooling as a disciplining technology shaping subjects for regimes of power under inequality. On this perspective, teachers' 'commitments to educational equity' are not merely "not enough" to break through the blame game, as the authors put it, but rather self-justifying rhetorical postures enabling complicity in these regimes.

Seen as such, the task for a democratic teacher education would involve preparing teachers not merely to "step outside the cycle of blame" but to step outside the entire rhetorical package of equity and merit., grasping that this package creates 'deficits' by forcing young bottom-dogs into compulsory, soul-destroying rat races designed to showcase their 'deficiencies' and 'demerits'. Once they grasp destructive power of this rhetoric, trainees might even worry about innocent-sounding phrases in RTE such as providing "well-developed curricula" and "facilitating robust learning for all students".

\section{Teacher Education Programs as Complex Organizations}

This leads me to offer an additional perspective on complexity and teacher education. Complexity theory as I understand it denotes a set of observations about similarities in seemingly unrelated systems: electrons, flocks of birds, markets, etc. Systems are sets of interacting parts behaving as a whole, whose function depends upon the nature and arrangement of the parts. Because the parts interact they are often referred to in complexity studies as agents. Systems may include diverse types of agents and employing diverse interaction strategies. The pattern of interactions among the parts determines the system's structure. Restructuring a system is changing the interaction patterns among the parts. Systems are complex to the extent that there are strong interactions among the parts, and interactions are likely to be strong to the extent that they involve many and diverse agents following diverse local rules or strategies. The first core observation of complexity theory is this: the stronger the interactions the more difficult it is to interpret, predict or control the system.

In complex adaptive systems, agents seek to adapt to changing conditions in the system or environment. Complex human systems are inherently adaptive. Historically, a primary goal of organizational leadership has been to reduce system complexity to maintain control. Schools are prime examples: officials reduce the diversity of agents (teachers and students) by confining them to one-size-fits-all treatment environments with fixed processes and aims. The limits with this reductionist paradigm were clear as soon as it 
was introduced: in such settings teachers can't draw on all of their diverse capabilities to teach, and students can't draw on all of their diverse capabilities to learn.

In the 1990s a conception of the "complex organization" evolved as one that explicitly recognized these limits of top-down organizational control. Instead of forcing control by suppressing complexity, such organizations consciously adapted to changing circumstances by releasing complexity and then harnessing the self-organizing results (Axelrod \& Cohen, 2000).

Changing the systems' control parameters, such as the number and diversity of interacting agents and strategies and the rate of flow of information, affects system stability and can prompt phase transitions at the edge of chaos. While these transitions can not be controlled, they can lead to the self-organized emergence of properties not previously witnessed in the system. A second key observation of complexity theory is this: it is possible to provoke phase transitions by manipulating a system's control parameters, even though is not possible to predict or control the transitions or determine the post-transition system. Order is maintained in complex organizations not through planning, strategy or tight control, but through coordination of creative local interactions.

We can conceive teacher education programs as complex organizations. A 'complex' program would reject one-size fits-all models of teacher training as suppressing the diversity of prospective teachers. Instead the program would seek to release this diversity and harness the resulting complexity, encouraging emergence of novel training activities from unpredicted interactions among staff and teacher trainees.

The programs leaders would not seek to impose a "well developed curriculum"; on the contrary, the 'curriculum' (if we would call it that) would grow out of unpredictable creative interactions among trainees and staff. Instead of 'planning' the program the leaders would establish a 'context' to 'contain' these self-organizing activities, to prevent them from falling over the edge of chaos into disorder. This program context would consist in purposes and governing principles, and a structural design providing for staff development and staff assignment to emerging activities, as well as for coordinating these activities to maintain program identity and durability amidst change (Haeckel, 1999).

Concretely, one primary purpose might be to improve teaching by discovering, enhancing, and utilizing in creative ways the multiple capabilities of prospective teachers, as individuals and as a cohort. Such capabilities might include e.g., computer programming, video editing, directing stage plays, managing and marketing events, conducting research, playing chess or computer games, performing environmental assessments, designing smart phone aps, and just about anything else. The ability effectively to convey school subject matters would be one, but only one, capability seen as useful in teaching.

In turn, the training program might evolve into a loose federation of activities including a group publishing venture, a research project, a local television series, a community assistance project, an after-school tutoring program. The program would model complex organization in such a way that trainees would learn to emulate it in 
schools by discovering, enhancing and utilizing student capabilities to generate federated learning projects.

Program leadership would encourage such ventures, manage control parameters to prevent stagnation, provoke new self-organizing activities, and coordinate them to maintain program identity and durability. Aware that the successful publishing house, television series or community assistance project may in time lose its value as a site of creative learning, program leaders would continually release the diversity in each new training cohort so that it generates its own unpredicted self-organizing activities for its changing times. Meanwhile leaders keep the system viable in the face of internal and external challenges, and maintain its identity as e.g., a community treasure and a source of exceptionally creative teachers.

\title{
References
}

Axelrod, R., \& Cohen, M. (2000). Harnessing complexity: Organizational implications of a scientific frontier. New York, NY: Free Press.

Haeckel, S. (1999). The adaptive enterprise: Creating and leading the sense and respond organization, Cambridge MA: Harvard Business Press.

Waldrop, M. (1992). Complexity: The emerging science at the edge of order and chaos. New York, NY: Simon and Schuster.

\begin{abstract}
About the Author
Leonard J. Waks received a Ph.D. in philosophy from University of Wisconsin (Madison) and an Ed.D. in Organizational Psychology from Temple. His work has focused on the intersection of education, technology and politics. He is co-founder of the National technological Literacy Conferences, and the author of more than 100 articles and book chapters and the book Technology's School (JAI, 1995). He retired from Temple in 2005 and is now Emeritus Professor of Educational Leadership and Policy Studies. He is currently writing a book on the intersection of the Interrnet and educational institutions.

(C) Copyright 2011. The author, Leonard J. Waks, assigns to the University of Alberta and other educational and non-profit institutions a non-exclusive license to use this document for personal use and in courses of instruction provided that the article is used in full and this copyright statement is reproduced. The author also grants a non-exclusive license to the University of Alberta to publish this document in full on the World Wide Web, and for the document to be published on mirrors on the World Wide Web. Any other usage is prohibited without the express permission of the authors.
\end{abstract}

